\title{
Retrospective Evaluation of Geriatric Inpatients with Nephrotic Syndrome: A Single Centre Experience
}

\author{
(1) Aslı Kılavuz, (1) Sumru Savaş, (1) Fulden Saraç, (D) Fehmi Akçiçek \\ Ege University Faculty of Medicine, Department of Internal Medicine, Division of Geriatrics, izmir, Turkey
}

\begin{abstract}
Objective: Nephrotic syndrome frequently develops because of primary kidney disease in older adults. The most common secondary cause is diabetic nephropathy. This study aims to investigate the frequency of nephrotic syndrome and the primary and secondary causes of nephrotic syndrome in hospitalised patients aged 65 years and over in our centre.
\end{abstract}

Materials and Methods: Patients aged 65 years and over who were hospitalised in the internal medicine clinic between 0ctober 2000 and 2014 using the "nephrotic syndrome" diagnostic code were selected from hospital records. Demographic, clinical, biochemical parameters and pathology results were examined retrospectively.

Results: A total of 92 patients were diagnosed with nephrotic syndrome. Thirty-one patients were included in the study after reviewing patient files (32.3\% female, 67.7\% male). In nine patients, biopsies were not performed because of general risk factors, atrophic kidney, bleeding diathesis and other reasons. The mean age was $72.6 \pm 5.2(65-87)$ years. The records indicated that $58 \%$ of patients were hypertensive, $26 \%$ were diabetic, $23 \%$ suffered from coronary artery disease, 58\% had hyperlipidaemia and 13\% had connective tissue disease. In the biopsy results, 40.8\% were diagnosed with membranous glomerulonephritis. Amyloidosis, diabetic nephropathy and focal segmental glomerulosclerosis diagnoses were present in $18.2 \%$, $18.2 \%$ and $13.6 \%$ of patients, respectively.

Conclusion: Membranous glomerulonephritis was the most common type of nephrotic syndrome in our centre in accordance with the literature in older patients. We found that amyloidosis and diabetic nephropathy ranked second. The present study demonstrated the importance of renal biopsy in the presence of nephrotic syndrome in older adults.

Keywords: Elderly, nephrotic syndrome, renal biopsy

\section{Introduction}

Progressing nephron loss in the kidneys, glomerular and tubulo-interstitial damage and a decline in kidney functions occur with increasing age (1). Those changes may make it difficult to interpret the kidney lesions. The increase in the permeability of glomerulus especially for macromolecules such as albumin, lead to proteinuria at nephrotic levels ( $>3.5 \mathrm{gr} / 24$ hour). As a result of this, hypoalbuminemia, hyperlipidemia, oedema and hypercoagulopathy may develop. These are the most significant factors that indicate morbidity and mortality for nephrotic syndrome. As one of the most frequently observed kidney diseases in older patients, nephrotic syndrome usually occurs due to primary glomerular diseases (2). Since the symptoms of nephrotic syndrome can be confused with congestive heart failure or venous insufficiency, it might be difficult to diagnose in older patients (3). In older patients, the most common forms of primary glomerular diseases are membranous glomerulonephritis and focal segmental glomerulosclerosis while the most common causes of secondary glomerular diseases are diabetic nephropathy, amyloidosis and malignancy $(3,4)$.

In the diagnostic assessment of nephrotic syndrome, the role of renal biopsy and identification of underlying causes are rather significant. For diagnosis, at first history of the patient, physical examination and serum biochemical examinations are assessed. In older patients, the underlying causes must be aimed for

Address for Correspondence: Aslı Kılavuz, Ege University Faculty of Medicine, Department of Internal Medicine, Division of Geriatrics, İzmir, Turkey E-mail: asli.kilavuz@ege.edu.tr ORCID: orcid.org/0000-0002-0474-9911

Received: 08.09.2020 Accepted: 24.11.2020

Cite this article as: Kılavuz A, Savaş S, Saraç F, Akçiçek F. Retrospective Evaluation of Geriatric Inpatients with Nephrotic Syndrome: A Single Centre Experience. Eur J Geriatr Gerontol 2021;3(1):25-28

${ }^{\circ}$ Copyright 2021 by the Academic Geriatrics Society / European Journal of Geriatrics and Gerontology published by Galenos Publishing House. 
the treatment of secondary nephrotic syndrome. On the other hand, for primary nephrotic syndrome, conservative treatment, overall precautions and disease specific treatments must be applied. The impact of nephrotic syndrome can be more severe for older patients, at the same time renal biopsy should not be avoided no matter what the age is (2). The aims of this study were to investigate the frequency of nephrotic syndrome, and its primary and secondary causes in hospitalized patients aged 65 years and over in our center.

\section{Materials and Methods}

Patients aged 65 years and over who were hospitalized in the internal medicine clinic between October 2000 and 2014 were screened using the "nephrotic syndrome" diagnostic code. The data of 92 patients was found but, after deeper investigation, 31 patients received the exact diagnosis of nephrotic syndrome. Age, gender, comorbidity information, smoking history, serum creatinine concentration, creatinine, protein level of 24-hour urine sample, serum albumin level, hemoglobin level, total cholesterol level and renal biopsy pathology reports of these patients were recorded from their files. Nephrotic syndrome has been identified as the combination of $3.5 \mathrm{gr} /$ day/1.73 $\mathrm{m}^{2}$ proteinuria in the 24-hour urine sample with oedema, hypoalbuminemia, hyperlipidemia and lipiduria.

This study was presented as an oral presentation at the International Academic Geriatrics Congress 2017 on April 1216, 2017, in Antalya, Turkey. This study was approved by the Institutional Ethical Review Board (number: 14-9.2/12).

\section{Statistics}

All the statistical analyses were done with the use of SPSS 20.0 statistics package (SPSS, Inc., Chicago, IL, USA). Normality was checked using the Shapiro-Wilk test. Descriptive statistical methods have been used. Parameters have been presented as average \pm standard deviation and number.

\section{Results}

Out of 31 patients with the exact diagnosis of nephrotic syndrome; 21 of them were men, 10 were women. The mean age of the patients was $72.6 \pm 5.2(65-87)$ years. $58 \%$ of the patients were hypertensive, $26 \%$ were diabetic, $23 \%$ suffered from coronary artery disease, 58\% had hyperlipidemia, and 13\% had connective tissue disease. Demographical, clinical and biochemical results are given in Table 1. Nine patients out of 31 were not implemented renal biopsies due to having general problems, respiratory problems, atrophic kidney disorder and hemorrhagic diathesis. The pathological results of 22 patients (8 female, 14 male) who underwent renal biopsies are given in Table 2. Renal biopsy results of four patients out of eight patients who had diabetes, indicated diabetic nephropathy. Three patients out of four patients who had amyloidosis had type amyloid A (AA) amyloidosis, and one had systemic non-AA amyloidosis.

\section{Discussion}

A higher frequency of renal diseases have been reported in older individuals in parallel to the growing numbers of this age group. Many studies have shown that nephrotic syndrome is the most common form of glomerular diseases among older patients $(2,5-$ 10). While the ratio of older patients who had renal biopsy is $8.2 \%$ between the years of 1995-1999; this ratio has increased to $15.1 \%$ between the years of 2000-2004. In younger adults, this ratio has been identified as $23.3 \%$ and $26.8 \%$ for the years 1999 and 2004, respectively. As can be understood, indications of renal biopsy in older adults increase while in younger adults it has always been high (11). Usually, since physicians believe

Table 1. Demographic, clinical and biochemical findings of older patients with nephrotic syndrome

\begin{tabular}{|c|c|}
\hline Variables & Values $(n=31)$ \\
\hline Age (years)* & $72.6 \pm 5.2$ \\
\hline $\begin{array}{l}\text { Gender, n (\%) } \\
\text { Male } \\
\text { Female }\end{array}$ & $\begin{array}{l}21(67.7) \\
10(32.3)\end{array}$ \\
\hline $\begin{array}{l}\text { Comorbidities, n (\%) } \\
\text { Hypertension } \\
\text { Diabetes mellitus } \\
\text { Coronary artery disease } \\
\text { Hyperlipidemia } \\
\text { Connective tissue disease }\end{array}$ & $\begin{array}{l}18(58) \\
8(26) \\
7(23) \\
18(58) \\
4(13)\end{array}$ \\
\hline Smoking, n (\%) & $6(19.3)$ \\
\hline Serum creatinine ${ }^{*}, \mathrm{mg} / \mathrm{dL}$ & $2.4 \pm 1.8$ \\
\hline Creatinine clearance $^{*}, \mathrm{~mL} /$ minute $/ 1.73 \mathrm{~m}^{2}$ & $42.5 \pm 29.0$ \\
\hline Protein in 24-hour urine ${ }^{*}, \mathrm{gr} / 24 \mathrm{~s}$ & $5.7 \pm 2.4$ \\
\hline Serum albumin*, g/dL & $2.8 \pm 0.9$ \\
\hline Hemoglobin*, g/dL & $11.4 \pm 2.12$ \\
\hline Total cholesterol*, mg/dL & $260.7 \pm 107.1$ \\
\hline
\end{tabular}

Table 2. Renal biopsy findings of older patients with nephrotic syndrome

Biopsy findings Number of cases, n (\%)

\begin{tabular}{|l|l|}
\hline \multicolumn{2}{|l|}{ Primary glomerular disease } \\
\hline Membranous glomerulonephritis & $9(40.8)$ \\
\hline Membranoproliferative glomerulonephritis & $1(4.6)$ \\
\hline Focal segmental glomerulosclerosis & $3(13.6)$ \\
\hline Secondary glomerular disease & $4(18.2)$ \\
\hline Amyloidosis & $4(18.2)$ \\
\hline Diabetic nephropathy & $1(4.6)$ \\
\hline Systemic lupus erythematosis & $22(100)$ \\
\hline Total &
\end{tabular}


that it is highly risky for older adults to have renal biopsies, it is difficult to identify the accurate prevalence of glomerular disease.

In the review by Burstein et al. (12), the nephrotic syndrome occurring in older patients was usually thought to be a symptom of another disease such as neoplasm. In our study, only three patients had hematologic malignancies but, no solid tumors were found in patients.

In the study by Galesic et al. (10), thirty-three older patients with nephrotic syndrome were examined. Membranous nephropathy was the most common histologic type, which was determined in 14 patients (42.4\%). Rapidly progressive glomerulonephritis was present in five patients (15.2\%). Other types of glomerular diseases were focal segmental glomerulosclerosis (18.2\%), diabetic nephropathy (3.0\%), mesangioproliferative glomerulonephritis (15.2\%), amyloidosis (3.0\%) and systemic lupus erythematosus (3.0\%). In our study, membranous glomerulonephritis, diabetic nephropathy and amyloidosis were present in $40.8 \%, 18.2 \%$ and $18.2 \%$ of patients, respectively. In both studies, the most common histological type was determined as membranous glomerulonephritis, but the ratios of other glomerular disease types were different.

In the prospective study of Fawcett et al. (13), 25 elderly patients and 75 young patients with nephrotic syndrome were included. Unlike this study, our study was a retrospective study and since young patients were not included, no comparison was made with young patients. In the aforementioned study, the minimal change disease has been found to be an important cause of nephrotic syndrome in the older patients as well as in younger patients, but minimal change disease hasn't been diagnosed in our study, so that renal biopsy is even more necessary in older nephrotic patients.

According to Fawcett et al. (13), 60\% of patients aged 60 years and over were diagnosed with nephrotic syndrome due to primary glomerular diseases, $12 \%$ due to amyloidosis and $28 \%$ due to other diseases (excluding diabetes). In our study, ratios of primary glomerular diseases and amyloidosis were found to be similar to the aforementioned study. Primary glomerular disease ratio was coherent with this study. However, no comparison could have been done for diabetic nephropathy ratio, as diabetic nephropathy was excluded. In our study, amyloidosis ratio $(18.2 \%)$ was found to be higher, compared to this study $(12 \%)$.

In the review by Cameron (2), membranous nephropathy was particularly common as a cause of the nephrotic syndrome in older patients (35\%), as well as minimal change disease (16\%) and primary amyloidosis (12\%). Therefore renal biopsy is even more necessary in older patients with nephrotic syndrome. In our study, membranous glomerulonephritis (40.8\%) has been found to be the most common cause, and amyloidosis ratio $(18.2 \%)$ was found be higher compared to this study. However, no minimal change disease was observed.

In a retrospective study, 76 nephrotic patients aged 50-84 years were analyzed. Primary glomerulonephritis was found to be more prevalent than secondary causes in older patients with nephrotic syndrome (5:2) (14). In our study, this rate was 13:9. In the aforementioned study, the most frequently observed primary glomerulonephritis forms were membranous glomerulonephritis and focal segmental glomerulosclerosis. The common type of secondary glomerulonephritis was lupus nephritis following by diabetic nephropathy and amyloidosis. Those findings support the results of the present study.

Ozono et al. (4) have demonstrated that membranous nephropathy was the most common type of primary nephrotic syndrome where amyloidosis and malignancy were common causes of secondary nephrotic syndrome in patients aged over 60 years. Likewise, in the present study, membranous glomerulonephritis was the most common type of primary Nephrotic syndrome, and amyloidosis was the most common secondary cause as well; however, no malignancy was observed.

In another study, like our results; Zech et al. (15) reported membranous glomerulonephritis (40\%) as the most frequently observed primary cause, and amyloidosis (13\%) as the most common secondary cause in patients with nephrotic syndrome aged 60 years and over.

In the present study, diabetic nephropathy was found in $18.2 \%$ of the cases (Table 2). This result is considerably different from the reports by Zech et al. (15) and by Kingswood et al. (16), in which its incidence was under $2 \%$. High frequency of diabetic nephropathy in our internal medicine clinic might be due to the diabetology section presence besides nephrology. A study in Japan also indicated high frequency of diabetic nephropathy in older adults with nephrotic syndrome. Thus, our result does not seem to be extreme. Moreover, we do not always perform renal biopsy in patients overtly supposed to have diabetic nephropathy. Such diabetic patients without biopsies were not included in this study. For this reason, we consider that exact percentage of diabetic nephropathy was higher than the result of our study.

In several studies, primary glomerular diseases were more common than secondary glomerular diseases in elderly patients with nephrotic syndrome. It was established that membranous glomerulonephritis was the most common primary disease while diabetic nephropathy and amyloidosis were the most common secondary glomerular diseases $(5,11,17)$. These results are also parallel to our study.

In a study by Oğuz et al. (18), the renal biopsy results from 12 older patients with nephrotic syndrome revealed that the most 
common type was amyloidosis, followed by minimal change disease, membranous glomerulonephritis and focal segmental glomerulosclerosis. The number of cases was lower than that determined in our study and the results were not compatible with our data.

\section{Study Limitations}

The limitation of our study was that we have screened the patients in the electronic patient data system using a diagnostic code, we could not reach the targeted patient number as patients' files were missing the diagnostic codes or the codes were entered as wrong. This may be the reason why some of our results were not coherent with the literature.

\section{Conclusion}

In our study, the most frequent cause of nephrotic syndrome observed in older patients was membranous glomerulonephritis which is coherent with the literature. The second most frequent causes that we observed in our patients were amyloidosis and diabetic nephropathy. Nine patients were not applied renal biopsies since high risks such as high risk general problems, atrophic kidney disorder and hemorrhagic diathesis. Therefore, pathologic diagnoses were not available. Percutaneous renal biopsy provides beneficial data on older adults since clinical situation and primary diagnosis can show differences. In this study, we emphasized the importance of histopathological diagnosis by renal biopsy in older patients. In addition, the frequency of glomerulonephritis causing nephrotic syndrome in older patients followed by a single center was determined.

\section{Acknowledgment}

We'd like to acknowledge Research Associate Hatice Uluer for the statistical analysis.

\section{Ethics}

Ethics Committee Approval: This study was approved by the Institutional Ethical Review Board (number: 14-9.2/12).

Informed Consent: Since the study is retrospective, there is no patient consent form.

Peer-review: Externally and internally peer-reviewed.

\section{Authorship Contributions}

Concept: A.K., S.S., F.S., F.A., Design: A.K., S.S., F.S., F.A., Data Collection or Processing: A.K., Analysis or Interpretation: A.K., S.S., F.S., F.A., Literature Search: A.K., S.S., F.S., Writing: A.K., S.S., F.A.
Conflict of Interest: No conflict of interest was declared by the authors.

Financial Disclosure: The authors declared that this study received no financial support.

\section{References}

1. Yavuz D, Yavuz R, Sezer S. Yaşlılık döneminde nefrolojik sorunlar. Turk Neph Dial Transpl 2012;21:217-223.

2. Cameron JS. Nephrotic syndrome in the elderly. Semin Nephrol 1996;16:319329.

3. Szmyt M, Niemir Zl, Czekalski S. Zespół nerczycowy u osób starszych. Najczestsze przyczyny zespołu nerczycowego w wieku podeszłym (cześć I) [Nephrotic syndrome in the elderly. The most frequent causes of the nephrotic syndrome in the elderly (part I)]. Pol Merkur Lekarski 2007;23:386390.

4. Ozono Y, Harada T, Yamaguchi K, Taura K, Hara K, Taguchi T. Nephrotic syndrome in the elderly--clinicopathological study. Nihon Jinzo Gakkai Shi 1994;36:44-50.

5. Nair R, Bell JM, Walker PD. Renal biopsy in patients aged 80 years and older. Am J Kidney Dis 2004;44:618-626.

6. Rivera F, López-Gómez JM, Pérez-Garcia $R_{i}$ Spanish Registry of Glomerulonephritis. Clinicopathologic correlations of renal pathology in Spain. Kidney Int 2004;66:898-904.

7. Shin JH, Pyo HJ, Kwon YJ, Chang MK, Kim HK, Won NH, Lee HS, Oh KH, Ahn C, Kim S, Lee JS. Renal biopsy in elderly patients: clinicopathological correlation in 117 Korean patients. Clin Nephrol 2001;56:19-26.

8. Prakash J, Singh AK, Saxena RK, Usha. Glomerular diseases in the elderly in India. Int Urol Nephrol 2003;35:283-288.

9. Davison AM. Renal disease in the elderly. Nephron 1998;80:6-16.

10. Galesic K, Ljubanovic D, Sabljar-Matovinovic M, Prkacin I, Horvatic I, Racic I. Nephrotic syndrome in the elderly. Acta Clin Croat 2003;42:337-340.

11. Uezono S, Hara S, Sato Y, Komatsu H, Ikeda N, Shimao Y, Hayashi T, Asada $Y$, Fujimoto S, Eto T. Renal biopsy in elderly patients: a clinicopathological analysis. Ren Fail 2006;28:549-555.

12. Burstein DM, Korbet SM, Schwartz MM. Membranous glomerulonephritis and malignancy. Am J Kidney Dis 1993;22:5-10.

13. Fawcett IW, Hilton PJ, Jones NF, Wing AJ. Nephrotic syndrome in the elderly. Br Med J 1971;2:387-388.

14. Jiratthawong $M$, Vongwiwatana $A$, Vareesangthip $K$, Vasuvattakul $S$, Chanchairujira T, Teerapornlertratt T, Parichatikanond P, Choensuchon B. Nephrotic syndrome in elderly patients: three years experience at Siriraj Hospital. J Med Assoc Thai 2011;94:111-116.

15. Zech $P$, Colon $S$, Pointet $P$, Deteix $P$, Labeeuw $M$, Leitienne $P$. The nephrotic syndrome in adults aged over 60: etiology, evolution and treatment of 76 cases. Clin Nephrol 1982;17:232-236.

16. Kingswood JC, Banks RA, Tribe CR, Owen-Jones J, Mackenzie JC. Renal biopsy in the elderly: clinicopathological correlations in 143 patients. Clin Nephrol 1984;22:183-187.

17. Sato H, Saito T, Furuyama T, Yoshinaga K. Histologic studies on the nephrotic syndrome in the elderly. Tohoku J Exp Med 1987;153:259-264.

18. Oğuz Y, Dede F, Ay AS, Karaman M, Eyileten T, Kırkpantur A, Yılmaz MI. Altmış Beş Yaş ve üzeri hastalarda böbrek biyopsisi: Bir klinikopatolojik analiz. Turk Neph Dial Transpl J 2010;19:174-179. 